\title{
PORTUGUÊS COMO LÍNGUA DE ACOLHIMENTO PARA ACESSO A DIREITOS HUMANOS: POLÍTICAS LINGUÍSTICAS E REFLEXÕES A PARTIR DA ANÁLISE DE MATERIAIS DIDÁTICOS PARA MIGRANTES
}

\author{
PORTUGUESE AS A HUMAN RIGHTS ACCEPTANCE LANGUAGE: \\ LANGUAGE POLICIES AND REFLECTIONS A PART OF ANALYSIS OF \\ MIGRANT TEACHING MATERIALS
}

Priscila de Pinho Valente ${ }^{1}$

\begin{abstract}
RESUMO
Diante da migração de senegaleses à cidade de Rio Grande, RS e das dificuldades linguísticas que encontram para suprir as suas necessidades de sobrevivência, percebemos a falta de uma política linguística de impacto social voltada para este grupo. Neste artigo, discutimos propostas metodológicas para o ensino de português como língua de acolhimento (GROSSO, 2010) para migrantes e refugiados a partir das políticas linguísticas adotadas no Brasil. Com base no referencial sobre Abordagem Orientada à Ação (JANOWSKA, 2014; PUREN, 2009) e Ensino de Línguas por Tarefas (ELLIS, 1991; 2000; JANOWSKA, 2014, SHIBAYAMA, 2017, WILLIS, 1996/2012) e na análise de alguns materiais didáticos específicos para imigrantes, serão analisadas as implicações de um ensino de língua estrangeira que vá além do viés do treino linguístico, visando o desenvolvimento de competências discursivas e promovendo a reflexão sobre a relação da língua com a garantia dos direitos humanos para a inserção plena dos migrantes na sociedade.
\end{abstract}

\section{Palavras-Chave}

Política linguística. Língua de acolhimento. Materiais didáticos.

\section{Abstract}

Faced with the migration of Senegalese people to the city of Rio Grande, RS and the linguistic difficulties that stand out as their survival needs, it is noticed a lack of a language policy of social impact aimed at this group. In this article, we discuss methodological proposals for the teaching of Portuguese as a hosting language (GROSSO, 2010) for migrants and refugees based on the language policies adopted in Brazil. According to Action-Oriented Approach on Language Teaching (JANOWSKA, 2014; PUREN, 2009), Task-based Approach (ELLIS, 2000; JANOWSKA, 2014, SHIBAYAMA, 2017, WILLIS, 2012) and the analysis of some specific didactic materials for immigrants, it will be presented a proposal of foreign language teaching that goes beyond the linguistic training, aiming at the development of discursive competences and promoting reflection on the relation of language with the guarantee of the human rights for the full integration of migrants into society.

\section{KeYwORDS}

Linguistic Policy. Hosting language. Teaching materials.

1 Mestra em Educação pela Universidade Federal de Pelotas, servidora pública do Instituto Federal de Educação, Ciência e Tecnologia do Rio Grande do Sul. 


\section{INTRODUÇÃo}

Há em Rio Grande, atualmente, em torno de 150 migrantes senegaleses, chegados ao município no período compreendido entre 2014 e 2018. Temos, diante deste dado, a necessidade de colaborar para a inserção dessa população na comunidade local com condições de exercício de cidadania. No que se refere à caracterização do grupo, os migrantes senegaleses que chegaram ao município não se enquadram como refugiados, mas sim como migrantes econômicos em busca de trabalho e melhores condições de vida que se depararam com algumas dificuldades, tais como: a barreira linguística, por não dominarem a língua portuguesa, e as diferenças socioculturais, como a religião, e seus horários para orações, e a divisão de tarefas entre homens e mulheres (uma vez que, em seu país de origem, homens não fazem tarefas consideradas femininas, como, por exemplo, aquelas relacionadas à limpeza da casa). Para a sua plena inserção na sociedade, isto é, para que consigam acessar a serviços básicos de saúde, lazer, educação, além do mercado de trabalho formal, consideramos que é imprescindível o ensino de português como língua de acolhimento. Frente a esta realidade, neste artigo, propomos uma reflexão sobre o contexto do ensino de Português como Língua de Acolhimento (PLAc) para migrantes na cidade de Rio Grande, RS e analisamos dois manuais para ensino de PLAc, em suas primeiras três unidades.

A motivação desta pesquisa é fruto de uma experiência pessoal desenvolvida nos últimos três anos com os migrantes senegaleses que estão residindo na Cidade de Rio Grande, RS, através do desenvolvimento, inicialmente do Projeto Intercâmbio Cultural: Brasil e Senegal, desenvolvido nos anos de 2016 e 2017, e atualmente do Projeto de Extensão Português como Língua de Acolhimento para Imigrantes Senegaleses, o qual se realiza através de uma parceria entre o Instituto Federal de Educação, Ciência e Tecnologia do Rio Grande do Sul-IFRS, a Universidade Federal do Rio Grande-FURG, a Prefeitura Municipal de Rio Grande, RS, e a Cáritas Diocesana de Rio Grande.

Com base em estudos sobre as políticas linguísticas (OLIVEIRA, 2001; SPOLSKY, 2016; SHOHAMY, 2006; CALVET, 2007; CARVALHO e SCHLATTER, 2011; GARCEZ e SCHULZ, 2016) e suas relações com as políticas de Estado desenvolvidas no Brasil no que se refere a migrantes (CONARE, Lei No. 9474 de 1997), pretendemos (1) descrever a distribuição de migrantes em Rio Grande, seu perfil e necessidades; (2) verificar como se configuram as concretas oportunidades para a sua formação/ escolarização, bem como as condições necessárias para isso; (3) propor a análise de alguns materiais didáticos disponíveis para o ensino de português para migrantes e suas implicações na prática docente.

Este artigo se compõe da seguinte estrutura: inicialmente, apresentamos a conceituação de políticas linguísticas e de sua estreita relação com as políticas de Estado. Na sequência, abordaremos o papel da língua portuguesa como língua de acolhimento para os migrantes e também questões teórico-metodológicas para o ensino de português como língua de acolhimento, isto é, na perspectiva de ensino a aprendizes em situação de refúgio e imigração. Por fim, apresentaremos a análise de unidades didáticas de alguns materiais disponíveis para o ensino de língua portuguesa para migrantes, tendo como norte a língua em uso/a partir da abordagem orientada para ação (JANOWSKA, 2014; PUREN, 2009) e da pedagogia de tarefas (ELLIS, 1991, 2000; JANOWSKA, 2014; SHIBAYAMA, 2017). Por fim, seguirão as considerações finais. 


\section{Políticas linguísticas no contexto de migrações, língua de ACOlHimento E ABORdagens AO ENSINO de PORTUGUÊS A MigRANTES}

Nesta seção, apresentamos alguns conceitos e referenciais teóricos os quais acreditamos que colaborarão para a proposta inicial de reflexão sobre o ensino de português para migrantes em situação de vulnerabilidade. A primeira parte da análise se refere aos conceitos de políticas linguísticas (OLIVEIRA, 2001) e de língua de acolhimento (GROSSO, 2010) para migrantes e refugiados. $\mathrm{Na}$ sequência, abordamos algumas teorias que podem auxiliar principalmente na elaboração da proposta pedagógica de ensino de língua para migrantes; são elas: Abordagem Orientada à Ação (JANOWSKA, 2014; PUREN, 2009) e Ensino de Línguas por Tarefas (ELLIS,1991, 2000; JANOWSKA, 2014; SHIBAYAMA, 2017; WILLIS, 1996/ 2012).

Como coloca Oliveira (2001), embora as políticas linguísticas estejam presentes na maioria das políticas educacionais e culturais, normalmente aparecem diluídas dentro de políticas culturais, educacionais, de inclusão ou de exclusão. Muitas vezes, aparecem como decisões técnicas, científicas, e não como decisões políticas, e, portanto, as relações de poder destas decisões são apagadas.

De acordo com Spolsky (2016), Shohamy (2006), Carvalho e Schlatter (2011), Garcez e Schulz (2016), políticas linguísticas podem ser entendidas como decisões sobre os usos da(s) língua(s), seus usuários e suas relações em diferentes domínios, cuja existência pode ter relação ou não com legislação ou normativas governamentais ou institucionais. Conforme Oliveira (2001), as políticas linguísticas definem como a língua do Estado funcionará, como se relacionará com os cidadãos, em que língua(s) a educação e os serviços culturais serão oferecidos e que variedade de língua será usada. A implementação dessas políticas depende de um planejamento linguístico, isto é, de ações concretas, sistêmicas, financiamento e orçamento, para que uma população inteira use a língua sem sofrer qualquer discriminação decorrente do preconceito linguístico.

Em relação à implementação dessas políticas, segundo Oliveira (2001), o Estado atua em duas frentes: as políticas linguísticas internas e as políticas linguísticas externas. As políticas internas são aquelas que atuam sobre as línguas faladas em território sob a gestão do Estado, isto é, abrangem a língua 'oficial' do país, além das línguas chamadas minoritárias, como as línguas indígenas, de imigração, de sinais, afro-brasileiras e as línguas estrangeiras ensinadas no sistema escolar do país, enquanto as políticas externas referem-se à postura dos países de língua portuguesa frente à gestão de internacionalização dessa língua.

A elaboração do Quadro Europeu Comum de Referência para línguas (CEFR, do inglês Common Framework of Reference for Languages) foi também resultado da preocupação de alguns governos atentos às questões de migração e integração dos migrantes com a sociedade. Dentre as ações de integração propostas, estão as políticas de acolhimento como o ensino das línguas oficiais dos países europeus como língua estrangeira. Entre as medidas sugeridas pelo Conselho da Europa aos Estados membros estão:

1. Assegurar, o melhor possível, que todos os sectores da população disponham de meios efectivos para adquirirem um conhecimento das línguas de outros Estados-membros (ou de outras comunidades no seio do seu próprio país), assim como as capacidades para o uso dessas mesmas línguas, de modo a permitir-lhes satisfazer as suas necessidades comunicativas e especialmente: 
1.1. lidar com situações da vida quotidiana noutro país e ajudar os estrangeiros residentes no seu próprio país a fazerem o mesmo;

1.2. trocar informações e ideias com jovens e adultos, falantes de uma outra língua e comunicar aos outros pensamentos e sentimentos;

1.3. adquirir um conhecimento mais vasto e mais profundo sobre o modo de vida e a mentalidade de outros povos, assim como sobre o seu património cultural.

2. Promover, encorajar e apoiar os esforços de professores e aprendentes, a todos os níveis, para que apliquem, de acordo com a sua situação, os princípios de implementação de sistemas de aprendizagem das línguas (tal como são progressivamente definidos no Programa das "Línguas Vivas" do Conselho da Europa):

2.1.baseando o ensino e a aprendizagem das línguas nas necessidades, motivações, características e recursos dos aprendentes;

2.2. definindo, com o máximo de rigor, objectivos válidos e realistas;

2.3. elaborando métodos e materiais adequados;

2.4. implementando modalidades e instrumentos adequados que permitam avaliar programas de aprendizagem.

3. Promover programas de pesquisa e de desenvolvimento que visem introduzir, em todos os níveis de ensino, métodos e materiais mais apropriados, de modo a permitir que diferentes grupos e tipos de aprendentes adquiram uma proficiência comunicativa adequada às suas necessidades específicas (CONSELHO DA EUROPA, 2001, p. 21).

A questão das políticas linguísticas voltadas para migrantes, atualmente, é altamente relevante no contexto brasileiro, uma vez que o Brasil entrou na rota das migrações nos últimos três anos, principalmente devido ao fechamento de fronteiras de outros países, como os Estados Unidos. Segundo entrevista sobre fluxo migratório, veiculada na TV Cultura, no programa Panorama (PANORAMA, 2018), a intensificação do fluxo de pessoas entre e em direção aos países da América Latina e Caribe, e dos movimentos migratórios oriundos da África e países como Síria, Líbano, Paquistão, Bangladesh, Nepal, Haiti, Bolívia, Angola e, mais recentemente, Venezuela, faz com que tenhamos que romper barreiras, linguísticas e sociais, e nos adaptarmos à perspectiva de multiculturalidade, acolhendo e respeitando a cultura do outro.

No Brasil, dados do Relatório do CONARE 2017 demonstram que o número de solicitações de refúgio cresceu exponencialmente, tendo sido reconhecidos, até o final de 2017, 10.145 refugiados de diversas nacionalidades. O ano de 2017 foi o mais expressivo em número de pedidos de refúgio, mesmo desconsiderando a chegada dos venezuelanos e dos haitianos. Foram 13.639 nesse ano, 6.287 em 2016, 13.383 em 2015 e 11.405 em 2014. No total, 33.866 pessoas solicitaram o reconhecimento da condição de refugiado no Brasil em 2017. Os venezuelanos representam mais da metade dos pedidos realizados, com 17.865 solicitações, números estes que tendem a aumentar em 2018 diante da crise que atinge a Venezuela.

Apesar dos contingentes migratórios ocorrerem em âmbito nacional, os desafios se manifestam em âmbito local, e as municipalidades precisam estar preparadas para enfrentá-los. Na maioria dos casos, o idioma é o primeiro desafio apresentado, e neste contexto, o ensino de português deve estar voltado para a integração desses indivíduos com a comunidade local. A seguir, abordaremos o conceito de língua de acolhimento, que relaciona os propósitos de aprendizagem da língua com as necessidades de sobrevivência no país de imigração. 


\section{Português como Língua de Acolhimento - PlAc}

Tradicionalmente, pensamos que a língua portuguesa como língua não materna seja uma língua estrangeira. A terminologia "língua estrangeira", contudo, não dá conta de todas as possibilidades de configuração da língua portuguesa para todos os falantes que não a têm como língua materna. A respeito disso, Bulla et al. contextualiza o termo língua adicional:

Em consonância com estudos e ações de Políticas Linguísticas iniciadas em outros países de imigrantes, como o Canadá, e com estudos da Organização das Nações Unidas para a Educação, a Ciência e a Cultura (UNESCO) (ver, por exemplo: JUDD, TAN \& WALBERG, 2001), utilizamos o termo língua adicional em contraposição a e visando a abarcar outras denominações como língua estrangeira, segunda língua, língua de herança ou língua de imigração ou acolhimento. Conforme discutido em Schlatter e Garcez (2009, p. 127-128), o termo língua adicional enfatiza o acréscimo a outras línguas que o aluno já tenha em seu repertório, ressaltando o caráter aditivo da língua sendo aprendida à vida do aluno e às possibilidades adicionais (que tal língua proporciona) de participação no mundo. Nesse sentido, tal termo torna relevante o fato de que a língua sendo aprendida é do aluno (não é estrangeira, como algo estranho, do outro, e que nunca será seu), é mais um recurso para sua participação e intervenção no mundo (JUDD, TAN \& WALBERG, 2001), e, ao mesmo tempo, não remete a categorizações aprioristas referentes às condições de aprendizagem da língua, a alguma suposta ordem de aprendizagem de línguas, às relações afetivas entre aluno e língua ou aos propósitos de aprendizagem. Sendo assim, a concepção de língua adicional torna indispensável a especificação de cada contexto de uso, ensino e aprendizagem de PLA, considerando cada participante, propósito, local etc. para a reflexão sobre a adequação ou não de PL (educacionais ou não) e de metodologias de ensino e aprendizagem de PLA. Há quem prefira, no entanto, a utilização das várias terminologias (BULLA et al., 2017, p. 7).

Nessa direção, o termo "língua adicional" inclui também a configuração da língua não materna para migrantes, como língua de acolhimento, terminologia aqui adotada. Para Grosso,

o conceito de língua de acolhimento aproxima-se da definição dos conceitos de língua estrangeira e língua segunda, embora se distinga de ambos. É um conceito que geralmente está ligado ao contexto de acolhimento, expressão que se associa ao contexto migratório, mas que, sendo geralmente um público adulto, aprende o português não como língua veicular de outras disciplinas, mas por diferentes necessidades contextuais, ligadas muitas vezes à resolução de questões de sobrevivência urgentes, em que a língua de acolhimento tem de ser o elo de interação afetivo (bidirecional) como primeira forma de integração (na imersão linguística) para uma plena cidadania democrática (GROSSO, 2010, p. 74).

Conforme já mencionamos anteriormente, o número de migrantes e refugiados tem crescido pelo mundo todo, e no Brasil não é diferente. Pelos dados do "Atlas Temático- Observatório de Migrações e Migrações Internacionais", recebemos cerca de 800 mil migrantes entre 2000 e 2015. Movidos por questões econômicas, políticas ou ambientais, os fluxos migratórios têm convergido cada vez mais para espaços alternativos, dentre os quais se encontra o Brasil. Aqui a acolhida aos refugiados é feita com base no Estatuto dos Refugiados, da Lei n. 9474 de 1997 - a "Lei do Refúgio" que criou o Comitê Nacional para os Refugiados (CONARE), cujo Artigo 1․ reportamos abaixo. 
Artigo $1^{\circ}$ - Será reconhecido como refugiado todo indivíduo que:

I - devido a fundados temores de perseguição por motivos de raça, religião, nacionalida-

de, grupo social ou opiniões políticas encontre-se fora de seu país de nacionalidade e não possa ou não queira acolher-se à proteção de tal país;

II - não tendo nacionalidade e estando fora do país onde antes teve sua residência habitual, não possa ou não queira regressar a ele, em função das circunstâncias descritas no inciso anterior;

III - devido a grave e generalizada violação de direitos humanos, é obrigado a deixar seu país de nacionalidade para buscar refúgio em outro país.

Apesar de a referida lei assegurar ao estrangeiro refugiado o direito à carteira de trabalho, à inscrição no Cadastro de Pessoa Física (CPF), à saúde e à educação pública, essa condição pode demorar para ser reconhecida. Agrava-se ainda mais quando os migrantes não se enquadram na condição de refugiados, como é o caso dos senegaleses que chegam a Rio Grande, à procura de melhores condições de vida. Sem documentos, não conseguem exercer o mínimo de cidadania, como alugar uma casa, matricular-se em escolas, ou até mesmo ter um emprego formal. Enfim, à medida que os migrantes chegam, fica evidente a precariedade de políticas públicas para a sua inserção produtiva, social e cultural.

Os migrantes, sejam eles considerados refugiados ou não, chegam ao Brasil oriundos de diversos países e por diferentes motivos que variam entre questões políticas, econômicas ou ambientais. Essa diversidade de nacionalidades revela outra dificuldade para os migrantes: a diversidade linguística. Como comunicar-se no país de acolhida com habitantes locais? Como estabelecer comunicação entre migrantes falantes de diferentes línguas?

Segundo Grosso,

Organizações não-governamentais e entidades ligadas a instituições religiosas têm assumido o papel que o governo ignora. O Centro de Apoio ao Migrante, citado anteriormente, e a Cáritas, em associação com o Alto Comissariado das Nações Unidas para Refugiados, promovem cursos gratuitos de português como língua estrangeira para imigrantes e refugiados, além de prestarem assistência jurídica e de colocação no mercado de trabalho (GROSSO, 2011, p. 03).

Várias instituições ligadas à sociedade civil, aos direitos humanos e às instituições religiosas vêm realizando um trabalho fundamental para a integração dos migrantes na sociedade. No município de Rio Grande, a Cáritas Diocesana de Rio Grande, através da Pastoral do Imigrante, instituição vinculada à Igreja Católica, vem auxiliando com as questões referentes à moradia, à assistência médica e jurídica e, ainda, articulando parcerias para empregar os migrantes. Em relação à língua, o auxílio chega através de voluntários e das instituições de Ensino, como a Universidade Federal do Rio Grande, que ofereceu curso de Português nos anos de 2014 e 2015, e, atualmente, o Instituto Federal de Educação do Rio Grande do Sul, em parceria com a Prefeitura Municipal de Rio Grande.

O desenvolvimento de políticas linguísticas para esse grupo é uma demanda atual, não apenas em relação ao ensino de português, mas também para proporcionar espaço de interação desses indivíduos com a sociedade local, evitando a sua exclusão cultural e social e a precarização de suas relações de trabalho. Em relação a migrantes e refugiados, costuma-se utilizar os termos língua 
de imigração, acolhimento, integração, as quais fazem referência aos propósitos de aprendizagem como relacionados a necessidades de sobrevivência e inclusão social no país de imigração.

Considerando a situação de integração, universidades brasileiras vêm implementando políticas públicas de ensino de português como língua de acolhimento para estrangeiros que chegam ao Brasil em situação financeira precária. Dentre estas iniciativas, podemos destacar, aqui no Rio Grande do Sul, o papel do GAIRE - Grupo de Assessoria a Imigrantes e Refugiados da Universidade Federal do Rio Grande do Sul (UFRGS), que promove encontros interdisciplinares sobre ensino de português para imigrantes e refugiados. Ainda sobre a língua de acolhimento, Cabete (2010) a conceitua como

um segundo idioma adquirido em contexto migratório em que os migrantes chegam ao novo país em caráter de miséria econômicos e/ou moral por serem obrigados a deixar seu país por conta de guerras causadas por conflitos políticos e religiosos ou desastres naturais (CABETE apud CURSINO et al., 2017, p. 320)

A aprendizagem da língua majoritária do país é, conforme Oliveira,

um importante meio de integração social por fornecer competências essenciais ao nível dos contatos pessoais e sociais, do desempenho e evolução escolares e profissionais e da resolução de problemas do quotidiano. Sabemos, contudo, que só os fatores linguísticos não garantem a plena cidadania desses indivíduos. Fatores externos como a necessidade urgente de aprendizagem para inserção no mercado de trabalho e integração na sociedade podem criar dificuldades para o processo de aprendizagem (OLIVEIRA, 2001 p. 63).

Pensando na interação em sociedade como objetivo final do ensino de português como língua de acolhimento, apresentaremos as duas teorias/ correntes que nortearão nossa proposta de ensino: Abordagem Orientada à Ação (JANOWSKA, 2014; PUREN, 2009) e Ensino de Línguas por Tarefas (ELLIS,1991, 2000; JANOWSKA, 2014; SHIBAYAMA, 2017, WILLIS, 1996/ 2012)

\section{Abordagem orientada À Ação}

No que se refere ao ensino de línguas estrangeiras, a corrente metodológica chamada Task-based Learning and Teaching, uma variante anglo-saxã da abordagem comunicativa na proposta de Ellis (2000), parece-nos bastante adequada pela contextualização das tarefas linguísticas em situações discursivas, situadas em contextos de interação social. Além disso, esta também é a perspectiva adotada pelo CEFR (Quadro Europeu Comum de Referência para línguas), cuja escolha, de acordo com Puren (2009), é também lógica, pois o objetivo apresentado nesse documento é de fato a formação de um “ator social”. Ainda segundo Puren (2002), o princípio da perspectiva acional é formar atores sociais com base no saber agir e não somente nas competências comunicativas e atos de fala da abordagem comunicativa.

Na metodologia tradicional formávamos um "leitor" fazendo-o traduzir (documentos), na metodologia ativa formávamos um "comentarista", fazendo-o falar sobre (documentos); na AC formávamos um "comunicador" criando situações linguísticas para fazê-lo falar com (interlocutores) e agir sobre (os mesmos interlocutores); na perspectiva acional desenhada pelo Quadro comum Europeu de Referência (para o qual utilizo a sigla "PA"), nos propomos a formar um "ator social"; que implica necessariamente, se quisermos continuar a aplicar o princípio fundamental da equivalência entre fins e meios, de fazê-los agir com outras pessoas durante o tempo da sua aprendizagem propondo-lhes opor- 
tunidades de "co-ação" no sentido de ações comuns a propósitos coletivos (PUREN, 2002:62 apud SHIBAYAMA, 2017, p.7).

A abordagem orientada à ação leva em conta um novo objetivo no ensino/aprendizagem de línguas, um objetivo social de preparar os aprendizes para que possam interagir em sociedade, com falantes de diferentes línguas e culturas estrangeiras, dentro e fora de seus países de origem. O caráter comunicativo da língua como ação é destacado pelo Quadro Europeu Comum de Referência para línguas

O uso de uma língua abrangendo a sua aprendizagem inclui as acções realizadas pelas pessoas que, como indivíduos e como actores sociais, desenvolvem um conjunto de competências gerais e, particularmente, competências comunicativas em língua. As pessoas utilizam as competências à sua disposição em vários contextos, em diferentes condições, sujeitas a diversas limitações, com o fim de realizarem actividades linguísticas que implicam processos linguísticos para produzirem e/ou receberem textos relacionados com temas pertencentes a domínios específicos. Para tal, activam as estratégias que lhes parecem mais apropriadas para o desempenho das tarefas a realizar (CEFR, 2001, p. 29).

Do ponto de vista da metodologia, conforme coloca Janowska (2014), a perspectiva acional reúne as práticas pedagógicas existentes, como a abordagem comunicativa, a abordagem por tarefas ou a abordagem por competências. A perspectiva acional compreende possibilidades de trabalho de sistematização, gramática ou vocabulário cada qual com sua importância dentro do planejamento e organização do projeto pedagógico através das tarefas.

O papel das tarefas/exercícios de pré-comunicação consiste em fornecer um meio que permitiria ao aluno construir competências de linguagem adaptadas a situações de comunicação. Deste modo, situamos a tarefa num eixo entre um polo autêntico e um polo pedagógico conforme ela se aproxima de uma prática linguística e/ou não linguística referente ao mundo real ou permite aos aprendizes desenvolver as competências necessárias para funcionar em situações comunicativas do mundo exterior (JANOWSKA, 2014, p. 67).

Amado (2012) reconhece, na Abordagem Comunicativa, a língua ensinada não como um conjunto de frases, mas como um conjunto de eventos comunicativos, cujas funções expressam o propósito para o qual ela é usada, em diferentes graus de complexidade linguística e em diferentes níveis de formalidade. O desenvolvimento de uma competência estratégica, como, por exemplo, saber como usar a língua para se comunicar, pode ser tão ou mais importante que a competência gramatical.

Ainda de acordo com Janowska (2014), partindo de uma perspectiva de aprendizagem vygotskiana, como um fenômeno social realizado nas interações com os outros, e de uma concepção teórica de uso da linguagem como prática socialmente construída, o conceito de tarefa traz uma nova dimensão para o processo de ensino aprendizagem, pois sua implementação se dá em um ambiente específico, com um propósito determinado (linguístico e/ou extralinguístico) e orienta o trabalho do aluno. O ensino de línguas, nessa perspectiva, não se restringe a apenas entender estruturas linguísticas, mas a possibilitar ao estudante desenvolver capacidades de participar de distintas atividades por meio da realização de ações pelo uso da linguagem. 
Por isso, consideramos relevante refletir sobre a construção de tarefas pedagógicas no contexto de ensino da língua portuguesa como língua de acolhimento para migrantes. Segundo Grosso (2007), "A realização de tarefas significativas em situações ricas e complexas contribui para o desenvolvimento de competências, designadamente das comunicativas". Por "tarefa" entende-se uma atividade orientada por objetivos na qual os alunos usam a linguagem para alcançar um resultado real.

Tarefa é um conceito-chave incluído no CEFR e traz uma nova dimensão para o processo de ensino/aprendizagem. Segundo o CEFR, "Define-se como tarefa toda intenção acional que, para o ator, representa a necessidade de chegar a um dado resultado em função de um problema para resolver, de uma obrigação para cumprir, de uma meta estabelecida" (CONSELHO DA EUROPA, 2001, p. 16 apud JANOWSKA, p.64, 2014). Willis (1996/ 2012) esclarece que "tarefas" não são atividades que envolvam o uso do idioma para simples prática sem nenhum propósito além de praticar uma linguagem pré-especificada. Para ela, tarefas devem proporcionar oportunidades de interação que buscam alcançar um resultado.

I would like to clarify here what tasks are not. Tasks - as defined above - do not include activities which
involve language use for practice or display, such as 'Describe the picture using some of the phrases below.'
Or 'Ask yourpartner if he likes the foods below using the forms 'Do you like' 'Yes I do,' 'No I don't.' or
role-plays which are pre-scripted, where there is no outcome or purpose other than practicing pre-specified
language. These might make perfectly good practice activities but they would not count as tasks, as here
the main focus is on using particular forms, not exchanging meanings to achieve an outcome.
To summarize briefy, if we believe that learners learn better through taking part in meaning-oriented
interactions, then we ought to be thinking in terms of providing such opportunities for interaction. It is
these that I am calling 'tasks' (WILLIS, 1996/2012, p. 3).'

Antes de seguirmos, contudo, é importante, assim como reconhece Janowska (2014), distinguir atividade pedagógica de tarefa pedagógica. Bulla, Lemos \& Schlatter (2012) definem tarefa pedagógica como um convite para que ações sejam realizadas conforme uma sugestão de enquadramentos de atividades futuras e sustentadas por objetivos educacionais, enquanto atividade pedagógica é definida como um conjunto de ações com o objetivo de realizar o que foi proposto em uma tarefa pedagógica, ou algo diferente, atividade emergente das interações e que pode servir para que os objetivos educacionais sejam reconfigurados in loco (BULLA; LEMOS; SCHLATTER, 2012, p.108).

$\mathrm{Na}$ atuação com a cultura do outro, precisamos relativizar concepções culturais, o que nos motiva a observar o contexto de ensino de português como língua de acolhimento a partir da abordagem intercultural, sobre a qual discorremos na próxima seção.

\footnotetext{
2 Eu gostaria de esclarecer aqui o que tarefas não são. Tarefas - como definido acima - não incluem atividades que envolvam o uso do idioma para prática ou exibição, como "Descreva a imagem usando algumas das frases abaixo" ou "Pergunte ao seu parceiro se ele gosta dos alimentos abaixo usando os formulários" como "Sim, eu faço", "Não, eu não faço" ou dramatizações que são pré-escritas, onde não há nenhum resultado ou propósito além de praticar uma linguagem pré-especificada. Estas podem ser atividades de boas práticas, mas não são consideradas tarefas, já que aqui o foco principal é usar formas específicas, não trocar significados para alcançar um resultado. Resumindo brevemente, se acreditarmos que os aprendizes aprendem melhor participando de interações orientadas para o significado, então deveríamos estar pensando em termos de proporcionar tais oportunidades de interação. São estes que estou chamando de tasks (Tradução minha).
} 


\section{Abordagem Intercultural}

As dificuldades sociais, interpessoais e educacionais dos migrantes, decorrentes do baixo domínio da língua local é cada vez mais evidente, diante da marginalização dos migrantes principalmente em relação ao mercado de trabalho. Uma forma de fomentar as políticas linguísticas inclusivas seria a promoção da integração da língua e de outros elementos culturais destes grupos à rotina escolar. É necessário estabelecer um elo entre a cultura e a motivação, afinal, como colocam Kraviski e Bergmann (2006, p.80), "a aprendizagem de uma língua estrangeira é diretamente afetada pela situação social, o contexto e a cultura da língua-alvo". As políticas educacionais, assim, devem estar voltadas para uma formação cidadã coerente com a diversidade linguística do Brasil contemporâneo e devem promover posturas linguísticas plurais e interculturais.

Assim, conhecer a cultura de um povo inclui conhecer a sua língua, e, se a motivação em aprendê-la está diretamente relacionada ao desejo de interação social, é preciso também entender como a cultura atua no processo de formação de falantes interculturais e agregá-la ao ensino de línguas, deixando de lado a ideia de ensino de línguas baseado puramente em treino para aquisição de estruturas gramaticais.

Segundo Kraviski e Bergamnn (2006), para o desenvolvimento da perspectiva de competência intercultural, o professor precisa levar em conta os valores interculturais envolvidos no processo de ensino-aprendizagem do aluno e dominar tanto a história e a cultura da língua que está ensinando, como a do seu próprio país. Assim, o ensino de uma língua adicional deverá considerar as culturas do povo que a tem como língua materna. Além disso, necessitará promover e divulgar, junto aos brasileiros, as culturas desses povos imigrantes, visando justamente à integração por meio do conhecimento da língua e da cultura do outro. Essa perspectiva intercultural, além de auxiliar na aprendizagem do idioma, incentivando a aluno a se aproximar da comunidade de falantes da outra língua, colabora na aceitação das diferenças, tolerância e respeito para com o próximo. Para Barbosa,

no contexto de ensino-aprendizagem de uma nova língua - cultura, o conceito de interculturalidade indica-nos possibilidades de aproximações entre essas duas dimensões. Trata-se de uma forma de mediação cultural da qual o aprendente participa, ao mesmo tempo em que reflete sobre sua cultura de origem e sobre a cultura da qual quer fazer parte. Essa reflexão ocorre, sobretudo, nas interações sociais cotidianas com a cultura que se pretende conhecer, quando o aprendente percebe, aos poucos, que apenas o domínio de aspectos linguísticos não é suficiente para ter acesso ao que Edward Hall (1971) denomina dimensões ocultas (BARBOSA, 2015, p. 1).

No projeto Português Brasileiro para Migração Humanitária (PBMIH) da Universidade Federal do Paraná (UFPR), estes temas são trabalhados, por exemplo, em parcerias com outras áreas, como História, Direito e Psicologia. No projeto, professores de História ministram cursos sobre história e civilização brasileira; o departamento jurídico da universidade auxilia os migrantes com a regularização de sua documentação; e o departamento de psicologia lhes fornece acompanhamento e atendimento clínico. Segundo Grosso (2011) "O ensino intercultural faz-se, portanto, necessário, pois é através dele que se pode promover o entendimento e a tolerância entre os povos”

$\mathrm{O}$ aprendente de uma língua torna-se plurilíngue e desenvolve a interculturalidade. As competências linguísticas e culturais [...] permitem, ao indivíduo, o desenvolvimento de uma personalidade mais rica e complexa, uma maior capacidade de aprendizagem lin- 
guística e também uma maior abertura a novas experiências culturais (CONSELHO DA EUROPA, 2001, p. 73).

Assim, com base nos referenciais teóricos da abordagem orientada à ação, do ensino baseado em tarefas e na abordagem intercultural já apresentados, além da análise das informações de que dispomos dos migrantes senegaleses, buscamos refletir a partir da análise das unidades iniciais de dois livros didáticos pensados especificamente para o ensino de português para migrantes. $\mathrm{Na}$ próxima seção, explicaremos os procedimentos metodológicos que utilizaremos para a formulação de tal proposta.

\section{Percurso de estudo}

O estudo aqui construído teve como base informações obtidas nos documentos da Pastoral do Imigrante no município de Rio Grande, RS, dos dados já levantados pelos projetos Intercâmbio Cultural: Brasil e Senegal, nos anos de 2016 e 2017, e Português como língua de acolhimento para os imigrantes Senegaleses, atualmente em andamento no Instituto Federal de Educação, Ciência e Tecnologia - Campus Rio Grande, além de reportagens veiculadas na mídia local. A discussão a ser desenvolvida terá por pressupostos teóricos aqueles referentes a política linguística, língua de acolhimento e abordagens ao ensino de português língua de acolhimento.

Através dos projetos mencionados, foram coletadas informações referentes a línguas faladas pelos estudantes, nível de escolarização, idade, número de alunos matriculados no projeto de língua portuguesa, índices de evasão, além de dados sobre as necessidades expressas pelo grupo para resolver questões do dia a dia, tais como: fazer compras, pegar ônibus ou preencher um formulário. Além disso, percebemos que os alunos estabeleceram um vínculo de amizade com os professores que se mostravam interessados em conhecer seus hábitos de vida, suas motivações para a saída do país de origem etc.

\section{Perfil do grupo}

Em relação à análise das informações levantadas a respeito do grupo de migrantes senegaleses que se inscreveram no projeto de aulas de português em 2018 (Anexo 1), obtivemos as seguintes informações: o grupo era inicialmente constituído por trinta pessoas, sendo a grande maioria homens e apenas uma mulher. As idades variavam entre 22 e 41 anos, e o nível de escolaridade ia desde analfabetos até indivíduos com nível superior, como Letras/ Francês e Filosofia. Muitos apenas estudaram nas escolas corânicas e, portanto, só estudaram o Alcorão em árabe e utilizam o wolof para se comunicar, já os que frequentaram as escolas do sistema educacional senegalês, também dominam o francês.

A grande maioria dos estudantes atua em postos de trabalho precários, como o comércio informal pelas ruas da cidade, ou ainda na construção civil e em fábricas da indústria pesqueira. Apesar de possuírem visto e carteira de trabalho, poucos estão trabalhando formalmente em postos de gasolina ou em empresas terceirizadas que atuam na limpeza do município. 


\section{Pontos de destaque Para a ANÁlise das propostas metodológicas e PEDAGÓGICAS}

Ainda em fase de elaboração, com base na experiência vivenciada nos projetos de extensão Intercâmbio Cultural Brasil e Senegal- IFRS e Português como Língua de Acolhimento para os migrantes Senegaleses, nas leituras dos relatos das memórias do Projeto Português Brasileiro para Migração Humanitária publicados pelo Celin-UFPR (RUANO et al., 2017), e em uma abordagem de ensino que considere as especificidades identitárias, políticas e sociais do grupo, procuramos organizar alguns pontos que entendemos sejam importantes para uma proposta de ensino voltada para os migrantes senegaleses que se estabeleceram no Município de Rio Grande, RS.

Primeiramente, um ponto que merece destaque é a importância em se conhecer a cultura dos migrantes para se conseguir formular propostas metodológicas e pedagógicas coerentes com o grupo. De acordo com Ngom (2010), apesar do Senegal ter o francês como língua franca, mais de $50 \%$ da sua população é considerada analfabeta em francês e, em sua maioria, utiliza o Wolof para se comunicar. A alfabetização em língua francesa, segundo o pesquisador, é restrita à minoria educada nas escolas estatais, grupo encontrado principalmente em áreas urbanas. O Wolofal (escrita árabe do Wolof) permanece sendo usado para escrever cartas, administrar seus negócios informais e ler poemas religiosos.

Ainda de acordo com Ngom, na sociedade predominantemente muçulmana do Senegal, na qual os líderes religiosos exercem um enorme poder social e político, a maioria das crianças são confiadas a marabus (professores) que as educam em escolas corânicas residenciais, chamadas daaras, onde estudam o Alcorão e a língua árabe durante um período que varia de três a quatro anos. A educação nas sociedades muçulmanas consiste tipicamente em três níveis. No primeiro nível, o único nível obrigatório, o Alcorão é introduzido em árabe e os alunos aprendem a observar as orações diárias, estudam a vida de profetas, e aprendem vários aspectos do Islã. Nestas instituições educacionais é que os falantes de wolof são inicialmente expostos à escrita árabe. Os demais níveis são para os que desejam continuar estudando sobre a religião.

Somente após a passagem por estas escolas, as crianças muçulmanas vão para a rede regular de ensino, onde aprendem as demais disciplinas e a língua oficial do país, o francês. À exceção de algumas escolas corânicas modernas - madrassas sustentadas pelo governo, que combinam o currículo corânico com o das escolas estatais, nenhuma das escolas corânicas do Senegal está sujeita a qualquer regulamento governamental e, portanto, não temos acesso a dados oficiais de evasão.

\footnotetext{
Although education (in French) is said to be compulsory for all children, the Senegalese Direction de la Prévision et de la Statistique indicates that the majority of the Senegalese people (63.4\%) can neither read nor write in any language.It also indicates that the illiteracy rate is higher in rural parts of the country where it is estimated at about $77 \%$ for people over 15 years $(1997,31)$. However, these statistics and those provided by UNESCO do not reflect the actual literacy rate in Wolofal and Ajami systems used for other local languages such as Pulaar and Mandinka, particularly in rural and religious centers across the country (NGOM, 2010, p. 2). ${ }^{3}$
}

\footnotetext{
3 Embora a educação (em francês) seja obrigatória para todas as crianças, a Direção de Pré-Observação e Estatística do Senegal indica que a maioria do povo senegalês $(63,4 \%)$ não sabe ler nem escrever em nenhum idioma. Também indica que a taxa de analfabetismo é maior nas partes rurais do país, onde é estimado em cerca de 77\% para pessoas com mais de 15 anos (1997, 31). No entanto, essas estatísticas e aquelas fornecidas pela UNESCO não refletem a taxa real de alfabetização em Wolofal e Ajami. sistemas
} 
Especificamente em relação a esse grupo, cuja maioria pratica a religião muçulmana, a questão dos horários de orações tem impacto direto na assiduidade dos alunos. Além disso, é preciso adequar os dias e horários das aulas à disponibilidade dos migrantes, uma vez que a grande maioria trabalha durante o dia no mercado informal pelas ruas da cidade. Sem respeitar estes dois pontos, temos grande probabilidade de altos índices de evasão. Um exemplo disto ocorreu no curso oferecido em 2017 no IFRS, que iniciou com 30 vagas ocupadas e, no final do ano, tinha apenas sete alunos assíduos, apesar de nunca pontuais.

A questão de nivelamento também é importante, pois temos diferentes perfis: adultos não alfabetizados em sua língua materna, adultos alfabetizados, mas com baixo nível de escolarização, e ainda adultos com nível de educação superior. Sem o correto nivelamento, muitos desistem, por considerarem o curso muito básico, por já dominarem determinados temas devido ao seu maior tempo de permanência no Brasil, ou muito difícil, para os que chegaram há pouco tempo e/ ou para os que têm baixa escolaridade. Como não há professores suficientes para mantermos mais de uma turma de projeto, após o nivelamento são formados grupos dentro da turma e são propostas atividades diferenciadas de acordo com o grau de conhecimento de cada grupo. Outro fator que dificulta o atendimento a estes alunos é que a maioria só domina o wolof, sua língua materna, restringindo o domínio do francês apenas àqueles com maior tempo de escolarização (curso técnico ou superior). Uma estratégia já utilizada pela equipe do projeto é solicitar que os senegaleses que já estão há mais tempo no Brasil deem apoio ao professor durante as aulas.

Um ponto interessante da proposta do projeto do Celin-UFPR (RUANO; SANTOS; SALTINI; 2017) o qual consideramos essencial diante da rotatividade de migrantes, é a questão da concepção de "ensino em trânsito". A proposta do grupo, baseada na teoria dos gêneros discursivos de Bakhtin, é de que cada aula seja uma tarefa comunicativa fechada, na qual, através de um tema condutor, sejam desenvolvidas competências para que o aluno seja capaz de desenvolver determinadas habilidades discursivas. O modelo tradicional, de abordagem linear, no qual uma aula seria a continuidade da outra, realmente não seria ideal para o grupo, pois a frequência às aulas não ocorre continuamente.

A ideia de trabalhar cada aula com um tema específico, de utilidade prática para os estudantes, como por exemplo: procura de emprego, acesso ao sistema de saúde, ida às compras no supermercado, vai além do ensino de língua propriamente dito; colabora para a inserção do estudante na sociedade.

Como já mencionamos, na abordagem intercultural, não podemos pensar a língua de forma isolada, portanto, o ideal seria trabalhar a questão linguística com a ajuda de uma equipe multidisciplinar que pudesse colaborar com outras demandas como questões de cunho psicológico, jurídico, social, como relatado nas experiências de Ruano et al. (2017) sobre os cursos de português como língua estrangeira no Projeto Português Brasileiro para Migração Humanitária do Celin - UFPR.

\section{Análise de manuais destinados a migrantes}

Com base no referencial teórico apresentado e, portanto, pensando na língua em uso/ na abordagem orientada para a ação, no conceito de tarefas e no padrão internacionalmente estabe-

utilizados para outras línguas locais, como Pulaar e Mandinka, particularmente em centros rurais e religiosos em todo o país (Tradução minha). 
lecido pelo Quadro Europeu Comum de Referência para Línguas, propomos a análise das primeiras três unidades dos dois manuais destinados a imigrantes: "Portas abertas" (REINOLDE et al., 2017), no Anexo 2, e "Pode entrar" (FEITOSA, et al., 2015), no Anexo 3, sob o olhar de que os imigrantes possam utilizar a linguagem, de acordo com o que coloca Bakhtin (2003), como "modo de ação social pelo uso situado e local de recursos sociais, linguísticos, históricos, estéticos, éticos culturais (compartilhados e sempre atualizados, criados e recriados intersubjetivamente) para fins de participação em diferentes esferas de atividade humana" (BAKHTIN apud BULLA; LEMOS; SCHATTER, 2012, p.108). A escolha pela análise das três unidades iniciais se deu justamente para verificar se o material poderia ser utilizado, por este grupo específico, conforme a sequência em que se apresenta, levando em consideração o nível de conhecimento da língua que os imigrantes possuem ao iniciarem as aulas.

Entendemos que a proposta de ensino de línguas para este público deve ter como norte o nível básico do CEFR-A1 (Iniciante). De acordo com o padrão internacionalmente estabelecido pelo Quadro Europeu Comum de Referência para Línguas (CONSELHO DA EUROPA, 2001) para descrever a proficiência em um idioma, o conhecimento dos alunos é divido em três categorias: Básico, Independente e Proficiente, cada uma com duas subdivisões. Segundo o Nível A1 do CEFR, resumidamente, em escala global,

\begin{abstract}
o indivíduo deve ser capaz de compreender e usar expressões familiares e cotidianas, assim como enunciados muito simples, que visam satisfazer necessidades concretas. Pode apresentar-se e apresentar outros e é capaz de fazer perguntas e dar respostas sobre aspectos pessoais como, por exemplo, o local onde vive, as pessoas que conhece e as coisas que tem. Pode comunicar de modo simples, se o interlocutor falar lenta e distintamente e se mostrar cooperante. (CEFR, 2001, p.49).
\end{abstract}

Assim, a partir das competências que se esperam do migrante Nível A1 do CEFR e do perfil de migrante com o qual estamos trabalhando no projeto de extensão em andamento Português como Língua de Acolhimento para Imigrantes Senegaleses, faremos uma breve análise dos materiais já mencionados, sempre sob uma perspectiva do ensino da Língua Portuguesa para atingir uma proficiência comunicativa adequada às suas necessidades específicas.

\title{
Análise das unidades Selecionados
}

Em relação à prática docente, também é preciso levar em conta o material didático. A maioria dos livros disponíveis no mercado são voltados para outro perfil de aluno e, portanto, não atingem as necessidades do grupo, tornando necessário que os docentes elaborem material específico.

$\mathrm{Na}$ busca por materiais didáticos disponíveis para se trabalhar em aulas com esse perfil de estudantes, encontramos dois livros voltados para migrantes: Pode entrar: Português para Refugiadas e Refugiados, desenvolvido conjuntamente pelo Alto Comissariado das Nações Unidas para Refugiados (ACNUR), o Curso Popular Mafalda e a Caritas Arquidiocesana de São Paulo (CASP) em 2015, e o livro Portas abertas: Português para imigrantes, resultado de um projeto organizado pela Prefeitura Municipal de São Paulo em cooperação com o Centro de Línguas da USP. Além de gratuitos, ambos estão disponíveis na internet para utilização junto a migrantes.

Segundo consta no texto introdutório da apostila "Portas abertas" (p.3), as autoras destacam a importância de capacitar linguisticamente os imigrantes e refugiados não só para a expressão co- 
tidiana, mas também para o esclarecimento de seus direitos, domínio e conhecimento do espaço, inserção digna na sociedade e no trabalho e pela troca intelectual. $\mathrm{Na}$ mesma direção, a apostila "Pode entrar" (p.3) destaca a importância da língua como elemento crucial para o desenvolvimento das relações e para as trocas culturais. Ambas se propõem a oferecer um material didático que auxilie o imigrante a dar os primeiros passos linguísticos para a sua integração ao país, porém não apontam qual a abordagem metodológica adotada. Podemos, contudo, inferir que o material "Pode entrar" trabalhe com a perspectiva de interculturalidade e abordagem orientada à ação, uma vez que em seu texto introdutório anuncia que em cada unidade apresentará uma proposta de atividade final (tarefa) que faça ligação com a história do país de origem do refugiado.

Ainda podemos verificar que, em ambos os materiais, as temáticas abordadas são assuntos relevantes para alunos migrantes, como por exemplo, mercado de trabalho, acesso a educação e saúde, entre outros, que assegurem a esses estudantes os direitos que eles têm enquanto cidadãos no Brasil. Ambos os manuais iniciam com práticas de apresentação pessoal, saudações etc., porém reservam grande parte da unidade para atividades de escrita e gramática, que, conforme a nossa experiência, podem se mostrar inviáveis para parte deste público específico que não lê nem escreve.

Em relação à compreensão escrita, segundo o Quadro Europeu Comum, espera-se que o indivíduo seja capaz de entender textos muito curtos e simples, descrições breves e simples, especialmente se houver ajuda visual, de seguir orientações escritas, curtas e simples, e de reconhecer nomes, palavras e expressões muito elementares que lhe sejam familiares, nas situações comuns do quotidiano. Já em relação à produção escrita geral, deve ser capaz de escrever expressões e frases simples acerca de si próprio e de pessoas imaginárias - onde vivem e o que fazem.

Assim, em relação aos migrantes atendidos pelo projeto de extensão, não sendo possível, durante as primeiras aulas, a leitura do material, optamos pela utilização de conversas e vídeos para facilitar as primeiras interações com o grupo e incentivar o diálogo em português.

No manual "Pode entrar", as informações que a primeira unidade apresenta são de extrema relevância prática para os migrantes, como: o conhecimento dos principais documentos que precisam providenciar para acesso ao Sistema Único de Saúde, as condições para a abertura de conta em banco e como preencher formulários. A primeira unidade (p.8-15) apresenta o alfabeto, números, saudações, pronomes pessoais, adjetivos possessivos, alguns verbos e tempos verbais e alguns exercícios de completar e preencher sobre o conteúdo gramatical abordado. A unidade encerra com uma atividade que consiste em fornecer dados pessoais em uma entrevista, de modo que o estudante descreva a si próprio, com suas informações pessoais. Essa escolha contempla o desenvolvimento de habilidades de produção oral que se espera de usuários de nível A1, de acordo com o CEFR. Há ainda um exercício de preenchimento de um formulário da Polícia Federal, que além de contemplar produção escrita, também auxilia na familiarização de documentos reais com os quais o migrante terá que lidar. A segunda unidade inicia com uma breve apresentação de diferentes nacionalidades, e em seguida, de conteúdos como alguns adjetivos que auxiliarão durante a descrição pessoal, números, pronomes interrogativos, verbos regulares e irregulares, conjugação no tempo presente, encerrando com solicitação de uma produção escrita sobre a origem do migrante.

$\mathrm{Na}$ terceira unidade analisada deste material o tema norteador é educação. O vocabulário apresentado gira em torno da escola. Este vocabulário é apresentado, sempre que possível, com 
sua respectiva representação visual através de desenhos, a fim de facilitar a compreensão pelo estudante. Além disso a unidade apresenta preposições, artigos e verbos. Os exercícios apresentados no fim da unidade se dividem em memorização de verbos e sua respectiva conjugação e a solicitação de uma produção escrita sobre educação no país de origem do migrante, atividade esta que além do conteúdo visto, adota uma perspectiva de interculturalidade, uma vez que proporciona uma troca entre o migrante e os colegas/professores sobre a cultura do outro.

Sob a perspectiva Acional defendida pelo CFER, de preparar os aprendizes para que possam interagir em sociedade, com falantes de diferentes línguas e culturas estrangeiras, dentro e fora de seus países de origem, o material aborda temas importantes, porém não deixa claro qual a tarefa / meta que deve ser alcançada ao final de cada unidade.

No que se refere ao manual "Portas abertas", as suas primeiras unidades concentram as atividades na apresentação pessoal e em dados demográficos e culturais do Brasil, (mais especificamente São Paulo, já que o material foi produzido pela USP) numa tentativa de ambientar o migrante. Na primeira unidade, apresentam-se as cores; na segunda, o alfabeto e saudações, com exercícios escritos de preenchimento de lacunas que necessitam do domínio da leitura e escrita, tanto para entender o que deve ser feito como para responder às atividades propostas (p.12-14). Os números também são apresentados primeiramente em uma grande tabela de numerais e por extenso (p.1516) seguidos de um exercício que parece não seguir no mesmo grau de dificuldade dos anteriores.

Somente na terceira unidade será abordada a apresentação pessoal através de um pequeno texto, o qual pode ser lido pelo professor, seguido de um questionário pessoal onde o aluno deve responder com seus dados objetivamente e escrever um texto se apresentando em uma rede social. Conforme já foi mencionado, de acordo com o Quadro Europeu, em relação à produção escrita, o usuário de nível A1 deve conseguir escrever expressões e frases simples sobre si mesmo. Nesta unidade também apresentam-se preposições, dias da semana, alguns verbos importantes para o dia-a-dia, horas, meses, estações do ano, e algumas expressões interrogativas. De fato, é nesta unidade que começam a aparecer conteúdos diretamente relevantes para o usuário, inclusive em relação aos temas abordados, tais como informações referentes a direito à documentação, CPF, Registro Nacional de Estrangeiro e carteira de trabalho.

Percebemos que a intenção, em ambos os materiais, é preparar o imigrante para as primeiras interações, habilitando-os a se apresentarem, se identificarem, dominarem alguns verbos básicos de ação, conhecer dias da semana, números, além de conseguirem formular perguntas básicas. Mesmo diante destes materiais didáticos para o contexto de ensino de PLAc disponíveis para acesso, as demandas específicas do grupo e outras limitações apresentadas, como a diferença de níveis de domínio do Português, e o baixo nível de domínio da escrita, fizeram com que optássemos por elaborar um material específico, considerando as necessidades de interação mais urgentes para os alunos e voltados para a perspectiva acional. Partindo do conceito de tarefa como uma intenção acional que busca alcançar um resultado em função de um problema para resolver, e que se dá em um ambiente específico, com um propósito determinado (linguístico e/ou extralinguístico) e que serviria para orientar o trabalho do aluno, pensamos em atividades que englobassem ações como: apresentação pessoal para dar respostas a órgãos públicos, acessar serviços, solicitar documentos, realizar vendas no comércio, entre outros. 
A consideração das necessidades é coerente com a perspectiva de acolhimento e com a perspectiva intercultural. Além disso, apesar dos materiais em questão não adotarem a abordagem orientada à ação de forma explícita, podem ser adaptados e constituírem um ponto de partida para o ensino de português para migrantes.

Sabendo que, de acordo com o nível A1 do Quadro Europeu Comum, o indivíduo deve ser capaz de produzir expressões orais simples e isoladas sobre pessoas e lugares, de descrever a si próprio, o que faz e onde mora, e de conseguir compreender um discurso com pausas longas que lhe permitam assimilar os significados, de entender instruções que lhe sejam dadas de forma clara e pausada e de seguir orientações simples e curtas, e com base nos pressupostos da abordagem orientada à ação, podemos propor tarefas partindo das produções orais, como, por exemplo, aquela descrita a seguir.

Como muitos senegaleses trabalham como vendedores ambulantes no comércio local e precisam negociar com seus clientes (necessidade), podemos propor tarefas as quais possibilitem que os estudantes sejam capazes de realizar uma negociação de compra e venda (propósito da interação). O objetivo da unidade precisa ficar claro para os alunos a fim de estimular a participação dos mesmos nas atividades de interação. A tarefa final poderia ser una encenação de venda, com negociação de preço, troca de informações sobre as características dos produtos e etc. Para isso podemos, por exemplo, durante a unidade apresentar alguns substantivos de acordo com os produtos que vendem, tais como: relógios, bolsas, meias; adjetivos como: caro/barato, bonito/ feio, bom/ ruim; alguns verbos voltados para compra e venda; além das cores, e dos números para cálculo de quantidade e preços.

Durante a tarefa, objetivo da aula, o aluno pode utilizar as estratégias propostas pelo Quadro, tais como: a aproximação ou generalização com uma linguagem mais simples; o feedback em expressões faciais, gestos que possibilitam o controle do resultado da comunicação, e ainda, para atividades não interativas como a escrita, a possibilidade da autocorreção.

A escolha dos temas trabalhados nos módulos deve ser feita com base no que elegemos como as prioridades apresentada pelo grupo de alunos, no caso do grupo de Senegaleses, elas estão basicamente relacionadas à apresentação pessoal, mundo do trabalho, hábitos alimentares, vida cotidiana, festas populares, entre outros, sempre relacionando com a cultura deles. Partindo de uma abordagem intercultural, estimulamos a troca entre aspectos da cultura brasileira com a cultura senegalesa buscando estabelecer um elo de empatia e respeito com os valores da cultura do outro.

Enfim, são diversos pontos que precisam ser analisados. Sabemos que estamos longe de uma abordagem ideal, mas seguimos em frente, dentro das limitações que encontramos, em busca de soluções concretas que possam colaborar para acolhimento destes migrantes.

\section{CONSIDERAÇões Finais}

Ao longo do presente artigo, destacamos a importância de discutir o ensino de português para imigrantes e refugiados, visto que as finalidades, as demandas e o contexto em que vivem são bastante divergentes da situação dos demais estrangeiros que chegam ao Brasil para turismo, estudo e trabalho. O ensino de língua portuguesa para imigrantes e refugiados, justamente pelas diferenças de condições, não pode ocorrer da mesma maneira do ensino de língua não materna para estran- 
geiros, onde se trabalha principalmente com o ensino prescritivo da língua e com o domínio da variante padrão.

Para tanto, o perfil deste imigrante precisa ser levado para o contexto de ensino de português para imigrantes e refugiados, pois os materiais didáticos comerciais disponíveis, na sua maioria, não contemplam a demanda. Dessa forma, o trabalho com materiais específicos, sejam eles adaptados ou não, precisa efetivamente estar voltado para o acolhimento do grupo.

Muito ainda deve ser feito em relação ao ensino de português como língua de acolhimento para os migrantes em situação de vulnerabilidade que chegam ao Brasil. São diversos os desafios para inseri-los na sociedade, desafios estes que envolvem diferentes esferas: social, política, econômica, cultural e linguística. Nós, como docentes de Língua Portuguesa, podemos colaborar neste processo de inclusão de diversas formas, seja atuando na formação docente, na produção de materiais ou ainda em pesquisas científicas que colaborem para uma prática mais efetiva e humana.

\section{REFERÊNCIAS}

ACNUR. Pode entrar: Português do Brasil para Refugiadas e Refugiados. Cartilha para Solicitantes de Refúgio no Brasil, 2015.

ACNUR. Disponível em: http://bit.ly/30oWYKn.

AMADO, R. S. Português segunda língua: perspectivas para a pesquisa linguística e o ensino pluri-e intercultural. Papia, Brasília, v. 22, 2012.

ARANTES, P. C. C.; DEUSDARÁ, B. Português para refugiados: aliando pragmática e discurso em resposta a uma demanda concreta. Letrônica, v. 8, n. 1, 2015, p. 45-59.

BAENINGER, R; FERNANDES, D. Atlas Temático - Observatório de migrações e migrações internacionais. São Paulo, 2018.

BAKHTIN, M. Estética da criação verbal. São Paulo: Martins Fontes, 2003.

BARBOSA, L. M. A. "Procedimentos Interculturais e Diversidade Étnico-Racial do Brasil em Dois Livros Didáticos de Português para Estrangeiros.” Revista Entrelínguas, v. 1, 2015, p. 223-236.

BARBOSA, L. M. A.; RUANO, B. P. "Acolhimento, sentidos e práticas de ensino de português para migrantes e refugiados na Universidade de Brasília e na Universidade Federal do Paraná", In: GEDIEL, J. A. P.; GODOY, G. G. (Orgs.). Refúgio e hospitalidade. Curitiba: Kairós Edições, 2016.

BRASIL. Migrantes, apátridas e refugiados: subsídios para o aperfeiçoamento de acesso a serviços, direitos e políticas públicas no Brasil. Brasília: Ministério da Justiça, Secretaria de Assuntos Legislativos (SAL): IPEA, 2015.

BULLA, G.; LEMOS, F.; SCHLATTER, M. Análise de material didático para o ensino de línguas adicionais a distância: reflexões e orientações para o design de tarefas pedagógicas. In: Horizontes de Linguística Aplicada, ano 11, n. 1, jan./jun., 2012, p. 103-135.

BULLA, G. S.; LAGES E SILVA, R.; LUCENA, J. C.; SILVA, L. P. Imigração, refúgio e políticas linguísticas no Brasil: Reflexões sobre escola plurilíngue e formação de professores a partir de uma prática educacional com estudantes haitianos. In: Revista Organon, v. 32, n. 62, 2017, p. 1-14.

CABETE, M. O processo de Ensino-Aprendizagem do Português enquanto Língua de Acolhimento. Dissertação (Mestrado em Língua e Cultura Portuguesa) - Universidade de Lisboa. Lisboa 2010.

CALVET, L. J. As políticas linguísticas. São Paulo: Parábola Editorial/IPOL, 2007.

COUNCIL OF EUROPE. Linguistic Integration od Adults Migrants. Literacy profiles: challenges in the migrant language education. Disponível em: http://bit.ly/2tlejrF.

CURSINO, C; ALBUQUERQUE, J; SILVA, M; GABRIEL, M; ANUNCIAÇÂO, R. Português brasileiro para migração humanitária (PBMIH): reflexões linguísticas e pedagógicas para o ensino de PLE em contexto 
de migração e refúgio. In: RUANO, B. P.; SANTOS, J. M. P.; SALTINI, L. M. L. Cursos de português como língua estrangeira no CELIN - UFPR: Práticas docentes e experiências em sala de aula. Curitiba: Editora UFPR, 2017.

CARVALHO, S. C.; SCHLATTTER, M. Ações de difusão internacional da língua portuguesa. In: Cadernos do IL, Porto Alegre, n. 42, 2011, p. 260-284.

FSL: French as a Second Language. Module 3. A Guide to Reflective Practice for Core French Teachers: The ActionOriented Approach.

ELLIS, Rod. Task-based research and language pedagogy. Language Teaching Research 4, 3, 2000, p. 193220.

ELLIS, R; FOTOS, S. Communicating about Grammar: A Task-Based Approach. Teachers of English to Speakers of Other Languages, Inc. TESOL Quarterly, v. 25, n. 4, 1991, p. 605-628.

FEITOSA, J; MARRA, J; FASSON, K; MOREIRA, N; PEREIRA, R; AMARO, T. Pode entrar. 1. ed., São Paulo, 2015. Disponível em: http://bit.ly/2Rj5dnb.

GROSSO, M. J. Línguas de acolhimento, língua de integração. Horizontes de Linguística Aplicada, v. 9, n. 2, 2010, p. 61-77.

GROSSO, M. J. Língua não materna-uma problemática conceptual. 2007.

KRAVISKI, E.; BERGMANN, J. Interculturalidade e motivação na aprendizagem de línguas estrangeiras. In: Revista Intersaberes, v. 1, n. 1, 2006, p. 78-86.

JANOWSKA, I. TAREFA UM CONCEITO-CHAVE DA PERSPECTIVA ACIONAL Task - $A$ key concept in the action-oriented approach. Dossiê especial: didática sem fronteiras. Revista X, v. 2, 2014. Disponível em: http://bit.ly/2TpdgS2.

MARTINS, B; ROCHA, D; SANTOS, J. Produção de materiais didáticos para o ensino de PLE do CelinUFPR: reflexões e desafios. In: RUANO, B. P.; SANTOS, J. M. P.; SALTINI, L. M. L. Cursos de português como língua estrangeira no CELIN - UFPR: Práticas docentes e experiências em sala de aula. Curitiba: Editora UFPR, 2017.

NGOM, F. Ajami scripts in the senegalese speech community. Journal of Arabic andIslamic Studies. Boston University, 2010 .

OLIVEIRA, G. Políticas linguísticas como políticas públicas. In: Bertussi, G. T. \& OURIQUES, N. D. (Coords.). Anuário Educativo Brasileiro: Visão Retrospectiva. São Paulo: Cortez, 2001, p. 313-333.

PERETI, E.; COSTA, E. I.; RAMMÉ, V. Tópicos avançados de língua-cultura brasileira: relato de uma experiência de curso especial de conversação em língua portuguesa. In: RUANO, B. P.; SANTOS, J. M. P.; SALTINI, L. M. L. Cursos de português como língua estrangeira no CELIN - UFPR: Práticas docentes e experiências em sala de aula. Curitiba: Editora UFPR, 2017.

PUREN, C. Variations sur le thème de l'agir social en didactique deslangues-cultures étrangères. Le Français dans la Monde. Recherches et applications, 2009.

QUADRO EUROPEU COMUM DE REFERÊNCIA PARA AS LÍNGUAS - Aprendizagem, ensino, avaliação. ASA Editores, Lisboa, Portugal, 2001.

REINOLDES, M; MANDALÁ, P; AMADO, R. Portas abertas, USP, São Paulo, 2017.

RUANO, B. P.; SANTOS, J. M. P.; SALTINI, L. M. L. Cursos de português como língua estrangeira no CELIN - UFPR: Práticas docentes e experiências em sala de aula. Curitiba: Editora UFPR, 2017.

RUANO, B; PERETI, E; GRAHL, J. Português brasileiro para migração humanitária (PBMIH): construindo um projeto de integração linguística, cultural e social. In: RUANO, B. P.; SANTOS, J. M. P.; SALTINI, L. M. L. Cursos de português como língua estrangeira no CELIN - UFPR: práticas docentes e experiências em sala de aula. Curitiba: Editora UFPR, 2017.

SCHLATTER, M.; GARCEZ, P. M. Línguas adicionais (Espanhol e Inglês). In: Rio Grande do Sul, Secretaria de Estado da Educação, Departamento Pedagógico. Referenciais curriculares do Estado do Rio Grande do Sul: linguagens, códigos e suas tecnologias. Porto Alegre: SE/DP, 2009, p. 125-172. 
SHIBAYAMA, A. N. A perspectiva acional no ensino de português como língua estrangeira. Simpósio 33 - A abordagem acional do português como língua estrangeira: o ensino baseado em tarefas, p. 3785-3804. Disponível em: http://bit.ly/2QXmdk8, 2017, Università del Salento.

SHOHAMY, E. G. Language policy: hidden agendas and new approaches. Abingdon, Inglaterra: Routledge, 2006.

SPOLSKY, B. Para uma teoria de políticas linguísticas. ReVEL, v. 14, n. 26, 2016, p. 32-44.

TV CULTURA: Fluxo Migratório Atual. 2018. Disponível em: http://bit.ly/35SS6P3.

WILLIS, J. A flexible framework for task-based learning An overview of a task-based framework for language teaching. A framework for task-based learning. ebook edition 2012. Disponível em: http://bit.ly/30elyh7.

Recebido em $7 / 8 / 19$ Aceito em $21 / 10 / 19$ 